\title{
Androgen receptor expression identifies patient with favorable outcome in operable triple negative breast cancer
}

\author{
Xiao-Qing Hu${ }^{1}$, Wei-Li Chen ${ }^{2}$, Hai-Guang $\mathrm{Ma}^{1}$ and $\mathrm{Ke}$ Jiang ${ }^{2}$ \\ ${ }^{1}$ Department of Surgical Oncology, Wenzhou Central Hospital, Zhejiang, China \\ ${ }^{2}$ Department of Breast Surgery, Yue Yang Hospital of Traditional Chinese \& Western Medicine, Shanghai University of \\ Traditional Chinese Medicine, Shanghai, China \\ Correspondence to: Ke Jiang, email: Surgeonjk@sina.com \\ Keywords: androgen receptor, triple negative breast cancer, prognostic biomarker, disease-free survival, overall survival \\ Received: December 27, $2016 \quad$ Accepted: March 15, $2017 \quad$ Published: April 07, 2017 \\ Copyright: $\mathrm{Hu}$ et al. This is an open-access article distributed under the terms of the Creative Commons Attribution License 3.0 \\ (CC BY 3.0), which permits unrestricted use, distribution, and reproduction in any medium, provided the original author and source \\ are credited.
}

\section{ABSTRACT}

In this study we sought to investigate the prevalence and prognostic value of androgen receptor (AR) status in operable triple-negative breast cancer (TNBC) patients. We collected the clinical data of $\mathbf{3 6 0}$ patients with TNBC, and found a positivity AR expression of $31.4 \%$ with a cut-off value of $10 \%$. Tumors expressing the negative CK5/ 6 $(P=0.013)$ and low $\mathrm{Ki}-67(P=0.007)$ are more likely to have positive $A R$. In multivariate survival analysis, AR expression is correlated with increased DFS (HR $=0.467,95 \% \mathrm{CI}$ $0.271-0.805 ; P=0.006)$ and $\mathrm{OS}(\mathrm{HR}=0.488,95 \% \mathrm{CI} 0.267-0.894, \mathrm{P}=0.020)$ independently. In addition, patients with AR+ tumors are more likely to have favorable outcome in patients with young, pre-menopausal, large tumor size, more node involvement (4+), high stage, high grade, vascular invasion+, P53+, CK5/6-, and higher Ki-67. Our study has indicated that the absence of AR might help to identify patients with relatively higher risk of disease relapse and death, and further clinical studies of anti-androgen agents are warranted to enrich the therapeutic strategy options for AR+ TNBCs.

\section{INTRODUCTION}

Breast cancer is a heterogeneous disease with several distinct subtypes that are based on differential patterns of gene expression. In recent years, breast cancers have been classified into four subtypes (luminal A, luminal B, HER-2 positive, and triple-negative) according to the status of hormonal receptors, Ki-67 and human epidermal growth factor receptor-2 (HER-2) expression [1]. Triplenegative breast cancer (TNBC), which lacks expression of estrogen receptor (ER), progesterone receptor (PR) and HER-2, is believed to have a relatively aggressive tumor biology [2]. Patients with TNBC have significantly worse prognosis compared to other breast cancer subtypes due to the lack of well-defined targeted molecular therapy [3].

Previous reports showed that TNBC could be classified into 7 subtypes by gene expression microarray $[4,5]$, indicated that TNBC is a heterogeneous disease comprising subtypes with different biological behaviors and treatment responses. It is recently reported that the seven-subtype system have been further modified [6].
However, compared to immunohistochemistry (IHC), gene-expression profiling is still premature in clinical practice. Thus, surrogate IHC markers have served as a more practical means of assessing preclinical and clinical predictive effects on tumor characteristics and patient outcome. For instance, androgen receptor (AR) could be detected by IHC to identify TNBC subset referred to as luminal androgen receptor subtype (LAR) [4].

Depending on the thresholds of positivity used, AR is expressed in $10-53 \%$ of TNBC, and positivity of only AR is far more common in patients than positivity in only ER, PR or HER-2 [7, 8]. The prognostic value of AR in TNBC varies among literatures. A meta-analysis included $2826 \mathrm{TNBC}$ patients suggested that absence of AR expression in TNBC served as a high-risk factor for both disease recurrence and death [9]. On the contrary, some other studies revealed that $\mathrm{AR}+\mathrm{TNBC}$ had worse survival $[4,10,11]$. In this study, we aimed to investigate the prevalence and prognostic value of AR status with a multicenter experience of Chinese women with TNBC. 
Table 1: Characteristics of patients according to AR status ( $n=360)$

\begin{tabular}{|c|c|c|c|c|}
\hline \multirow{2}{*}{ Characteristics } & \multicolumn{3}{|c|}{ Number of patients } & \multirow{2}{*}{$P$ value } \\
\hline & All & AR- (\%) & $\mathrm{AR}+(\%)$ & \\
\hline Age & & & & 0.557 \\
\hline$<40$ & 41 & $30(73.2 \%)$ & $11(26.8 \%)$ & \\
\hline $40-60$ & 228 & $154(67.5 \%)$ & $74(32.5 \%)$ & \\
\hline$>60$ & 91 & $58(63.7)$ & $33(36.3 \%)$ & \\
\hline Menopausal status & & & & 0.037 \\
\hline Pre & 150 & $110(73.3 \%)$ & $40(26.7 \%)$ & \\
\hline Post & 210 & $132(62.9 \%)$ & $78(37.1 \%)$ & \\
\hline Tumor size & & & & 0.133 \\
\hline$<2 \mathrm{~cm}$ & 184 & $117(63.6 \%)$ & $67(36.4 \%)$ & \\
\hline $2-5 \mathrm{~cm}$ & 176 & $125(71.0 \%)$ & $51(29.0 \%)$ & \\
\hline Node status & & & & 0.561 \\
\hline 0 & 227 & $148(65.2 \%)$ & $79(34.8 \%)$ & \\
\hline $1-3$ & 74 & $52(70.3 \%)$ & $22(29.7 \%)$ & \\
\hline $4+$ & 59 & $42(71.2 \%)$ & $17(28.8 \%)$ & \\
\hline Stage & & & & 0.166 \\
\hline I & 125 & $76(60.8 \%)$ & $49(39.2 \%)$ & \\
\hline II & 176 & $124(70.5 \%)$ & $52(29.5 \%)$ & \\
\hline III & 59 & $42(71.2 \%)$ & $17(28.8 \%)$ & \\
\hline Grade & & & & 0.007 \\
\hline I-II & 186 & $137(73.7 \%)$ & $49(26.3 \%)$ & \\
\hline III & 174 & $105(60.3 \%)$ & $69(39.7 \%)$ & \\
\hline Vascular invasion & & & & 0.748 \\
\hline- & 277 & $185(66.8 \%)$ & $92(33.2 \%)$ & \\
\hline+ & 83 & $57(68.7 \%)$ & $26(31.3 \%)$ & \\
\hline P53 & & & & 0.013 \\
\hline- & 143 & $107(74.8 \%)$ & $36(25.2 \%)$ & \\
\hline+ & 217 & $135(62.2 \%)$ & $82(37.8 \%)$ & \\
\hline CK5/6 & & & & 0.013 \\
\hline- & 214 & $133(62.1 \%)$ & $81(37.9 \%)$ & \\
\hline+ & 146 & $109(74.7 \%)$ & $37(25.3 \%)$ & \\
\hline Ki-67 & & & & 0.007 \\
\hline$<15 \%$ & 83 & $57(68.7 \%)$ & $26(31.3 \%)$ & \\
\hline $15 \%-50 \%$ & 129 & $74(57.4 \%)$ & $55(42.6 \%)$ & \\
\hline $50 \%-100 \%$ & 148 & $111(75 \%)$ & $37(25.0 \%)$ & \\
\hline Operation & & & & 0.932 \\
\hline BCS & 25 & $17(68.0 \%)$ & $8(32.0 \%)$ & \\
\hline Mastectomy & 335 & $225(67.2 \%)$ & $110(32.8 \%)$ & \\
\hline Chemotherapy & & & & 0.550 \\
\hline None & 26 & $20(76.9 \%)$ & $6(23.1 \%)$ & \\
\hline $\mathrm{CEF}$ & 146 & $97(66.4 \%)$ & $49(33.6 \%)$ & \\
\hline CEF-T & 188 & $125(66.5 \%)$ & $63(33.5 \%)$ & \\
\hline
\end{tabular}

(Continued) 


\begin{tabular}{lcccc}
\hline \multirow{2}{*}{ Characteristics } & \multicolumn{3}{c}{ Number of patients } & \multirow{2}{*}{$\boldsymbol{P}$ value } \\
\cline { 2 - 4 } Radiotherapy & All & AR- (\%) & AR+ (\%) & 0.089 \\
$\quad$ Yes & 113 & $83(73.5 \%)$ & $30(26.5 \%)$ & \\
No & 247 & $159(64.4 \%)$ & $88(35.6 \%)$ & \\
All & 360 & $247(68.6 \%)$ & $113(31.4 \%)$ & \\
\hline
\end{tabular}

$\mathrm{AR}$, androgen receptor; BCS, breast conserving surgery; CEF, cyclophosphamide+epirubicin +5 -fluorouracil; CEF-T, cyclophosphamide+epirubicin+5-fluorouracil followed by taxol.

\section{RESULTS}

\section{Patients' characteristics}

A total of 360 patients with TNBC were enrolled in this study. The characteristics of the patients are shown in Table 1. Among 360 patients, the median age was 52 (ranges 21-89), and

$41.7 \%$ of them were pre-menopausal. 125 patients were considered stage I disease, whereas 176 were considered Stage II and 59 were considered as stage III disease. Most of patients were diagnosed as invasive ductal carcinoma (344), whereas only 16 patients were of other histological types (7 metaplastic carcinoma, 3 lobular carcinoma, 3 micropapillary carcinoma, 1 medullary carcinoma, 1 mucinous adenocarcinoma and 1 adenocystic carcinoma). Majority of patients received mastectomy (335) and the other 25 patients received BCS. Chemotherapy was performed in $92.8 \%$ of patients, and radiation therapy was performed in $31.4 \%$ of patients. Among 360 patients, 113 (31.4\%) was AR+. Table 1 shows the patient characteristics according to AR category. A higher proportion of positive AR were most likely to be observed in patients with post-menopausal status $(\mathrm{P}=0.037)$, grade III $(\mathrm{P}=0.007), \mathrm{P} 53+(\mathrm{P}=0.013), \mathrm{CK} 5 / 6$ $(\mathrm{P}=0.013)$, and lower $\mathrm{Ki}-67$ value $(\mathrm{P}=0.007)$. However, the expression of AR was not correlated to patient age, tumor size, node status, stage, and vascular invasion or treatment strategies.

\section{Survival and prognostic factors}

The median follow-up time was 64 months. For 360 patients, the 5-year DFS was $75 \%$ and the 5-year OS was $80 \%$. Table 2 shows the result of univariate and multivariate survival analyses. Tumor size $(\mathrm{P}<0.001)$, node status $(\mathrm{P}<0.001)$, stage $(\mathrm{P}<0.001)$, grade $(\mathrm{P}=0.021)$, vascular invasion $(\mathrm{P}<0.001), \mathrm{AR}(\mathrm{P}=0.005)$, chemotherapy $(\mathrm{P}-=0.028)$, radiotherapy $(\mathrm{P}<0.001)$ were significant predictors of DFS and were entered into the multivariate Cox regression model with forward selection. Tumor size $(\mathrm{P}=0.002)$, node status $(\mathrm{P}<0.001)$, stage $(\mathrm{P}<0.001)$, vascular invasion $(\mathrm{P}<0.001), A R$ $(\mathrm{P}=0.019)$, radiotherapy $(\mathrm{P}<0.001)$ were also predictors of OS. In the multivariate Cox model, AR showed an independent prognostic value for both $\mathrm{DFS}$ ( $\mathrm{HR}=0.467$, 95\% CI 0.271-0.805; $\mathrm{P}=0.006)$ and $\mathrm{OS}(\mathrm{HR}=0.488$, $95 \%$ CI $0.267-0.894, \mathrm{P}=0.020)$. Node status was also an independent predictor of patient outcome $(\mathrm{P}<0.001$ for both DFS and OS). Better survival was more frequently observed in patients with positive AR and fewer involved nodes. The distributions of the survival curves by AR are shown in Figure 1A and 1B (log-rank test, $\mathrm{P}=0.003$ for DFS and $\mathrm{P}=0.016$ for OS). Combined with node status (shown in Figure 1C and 1D), patients with AR+ and node- have favorable outcomes with an observed 5 -year DFS of $92 \%$ and an observed 5 -year OS of $93 \%$. However, patients with AR- and node+ were at relatively higher risk of relapse and death (5-year DFS of $51 \%$ and 5 -year OS of $60 \%$ ).

We also investigated the prognostic value of $A R$ in patient subgroups. Table $3 \mathrm{~A}$ and $3 \mathrm{~B}$ show the HR and $95 \% \mathrm{CI}$ of $\mathrm{AR}$, demonstrating the prognostic strength for DFS and OS. AR positivity was correlated to better survival compared to AR negativity in most subgroups. The prognostic value of AR were statistically significant in patients with age of 40-60, pre-menopausal status, large tumor size $(2-5 \mathrm{~cm})$, more node involvement $(4+)$, high stage (III), high grade (III), vascular invasion+, P53+, CK5/6-, and higher Ki-67 (50\%-100\%).

\section{DISCUSSION}

Breast cancer has long been recognized as a heterogeneous disease. While the intrinsic subtypes of breast cancer based on gene array analysis has already been discussed, the IHC detection of receptor status is regarded as the most useful method in predicting prognosis and responsiveness to treatment. Breast cancer that lacks ER, PR and overexpression of HER-2, known as TNBC, is not amenable to the currently available targeted therapies and has a poor prognosis. Compared with other breast cancer subtypes, TNBC has a higher response rate to neoadjuvant chemotherapy; however, this advantage is not clearly translated into an improved overall survival [12]. This so-called TNBC paradox might be related to the heterogeneity of TNBC, and has attracted great attention of clinicians and researchers. Treating TNBC has always been challenging because of the heterogeneity and the absence of well-defined molecular targets. Previous reports 
Table 2: Univariate and multivariate survival analysis of TNBC patients $(n=360)$

\begin{tabular}{|c|c|c|c|c|c|c|c|}
\hline \multirow{3}{*}{ Characteristics } & \multirow{3}{*}{$\mathbf{N}$} & \multicolumn{3}{|c|}{ Disease-free survival } & \multicolumn{3}{|c|}{ Overall survival } \\
\hline & & $\mathbf{U v}$ & & $\mathbf{M v}$ & $\mathbf{U v}$ & & $\mathbf{M v}$ \\
\hline & & $\mathbf{P}$ & $\mathbf{P}$ & HR (95\%CI) & $\mathbf{P}$ & $\mathbf{P}$ & HR (95\%CI) \\
\hline Age & & 0.982 & - & - & 0.972 & - & - \\
\hline$<40$ & 41 & & & & & & \\
\hline $40-60$ & 228 & & & & & & \\
\hline$>60$ & 91 & & & & & & \\
\hline Menopausal status & & 0.671 & - & - & 0.878 & - & - \\
\hline Pre & 150 & & & & & & \\
\hline Post & 210 & & & & & & \\
\hline Tumor size & & $<0.001$ & 0.018 & & 0.002 & NS & - \\
\hline$<2 \mathrm{~cm}$ & 184 & & & Ref. & & & \\
\hline $2-5 \mathrm{~cm}$ & 176 & & & $1.731(1.097-2.734)$ & & & \\
\hline Node status & & $<0.001$ & $<0.001$ & & $<0.001$ & $<0.001$ & \\
\hline 0 & 227 & & & Ref. & & & Ref. \\
\hline $1-3$ & 74 & & & $1.858(1.024-3.369)$ & & & $1.992(1019-3.893)$ \\
\hline $4+$ & 59 & & & $6.362(3.913-10.343)$ & & & $7.685(4.458-13.247)$ \\
\hline Stage & & $<0.001$ & NS & - & $<0.001$ & NS & - \\
\hline I & 125 & & & & & & \\
\hline II & 176 & & & & & & \\
\hline III & 59 & & & & & & \\
\hline Grade & & 0.021 & NS & - & 0.111 & - & - \\
\hline I-II & 186 & & & & & & \\
\hline III & 174 & & & & & & \\
\hline Vascular invasion & & $<0.001$ & NS & - & $<0.001$ & - & - \\
\hline- & 277 & & & & & & \\
\hline+ & 83 & & & & & & \\
\hline P53 & & 0.158 & - & - & 0.713 & - & - \\
\hline- & 143 & & & & & & \\
\hline+ & 217 & & & & & & \\
\hline $\mathbf{A R}$ & & 0.005 & 0.006 & & 0.019 & 0.020 & \\
\hline- & 242 & & & Ref. & & & Ref. \\
\hline+ & 118 & & & $0.467(0.271-0.805)$ & & & $0.488(0.267-0.894)$ \\
\hline CK5/6 & & 0.552 & - & - & 0.505 & - & - \\
\hline- & 214 & & & & & & \\
\hline+ & 146 & & & & & & \\
\hline Ki-67 & & 0.599 & - & - & 0.735 & - & - \\
\hline$<15 \%$ & 83 & & & & & & \\
\hline $15 \%-50 \%$ & 129 & & & & & & \\
\hline $50 \%-100 \%$ & 148 & & & & & & \\
\hline Operation & & 0.367 & - & - & 0.546 & - & - \\
\hline $\mathrm{BCS}$ & 25 & & & & & & \\
\hline Mastectomy & 335 & & & & & & \\
\hline
\end{tabular}

(Continued) 


\begin{tabular}{|c|c|c|c|c|c|c|c|}
\hline \multirow{3}{*}{ Characteristics } & \multirow{3}{*}{$\mathbf{N}$} & \multicolumn{3}{|c|}{ Disease-free survival } & \multicolumn{3}{|c|}{ Overall survival } \\
\hline & & $\mathbf{U v}$ & & Mv & $\mathbf{U v}$ & & Mv \\
\hline & & $\mathbf{P}$ & $\mathbf{P}$ & HR (95\%CI) & $\mathbf{P}$ & $\mathbf{P}$ & HR $(95 \% \mathrm{CI})$ \\
\hline Chemotherapy & & 0.028 & NS & - & 0.214 & - & - \\
\hline None & 26 & & & & & & \\
\hline $\mathrm{CEF}$ & 146 & & & & & & \\
\hline CEF-T & 188 & & & & & & \\
\hline Radiotherapy & & $<0.001$ & NS & - & $<0.001$ & NS & - \\
\hline Yes & 113 & & & & & & \\
\hline No & 247 & & & & & & \\
\hline
\end{tabular}

Uv, univariate analysis; Mv, multivariate analysis; HR, hazard ratio; CI, confidence interval; NS, no significance; Ref, reference; AR, androgen receptor; BCS, breast conserving surgery; $\mathrm{CEF}$, cyclophosphamide+epirubicin+5-fluorouracil; CEF-T, cyclophosphamide+epirubicin+5-fluorouracil followed by taxol.

\section{A}
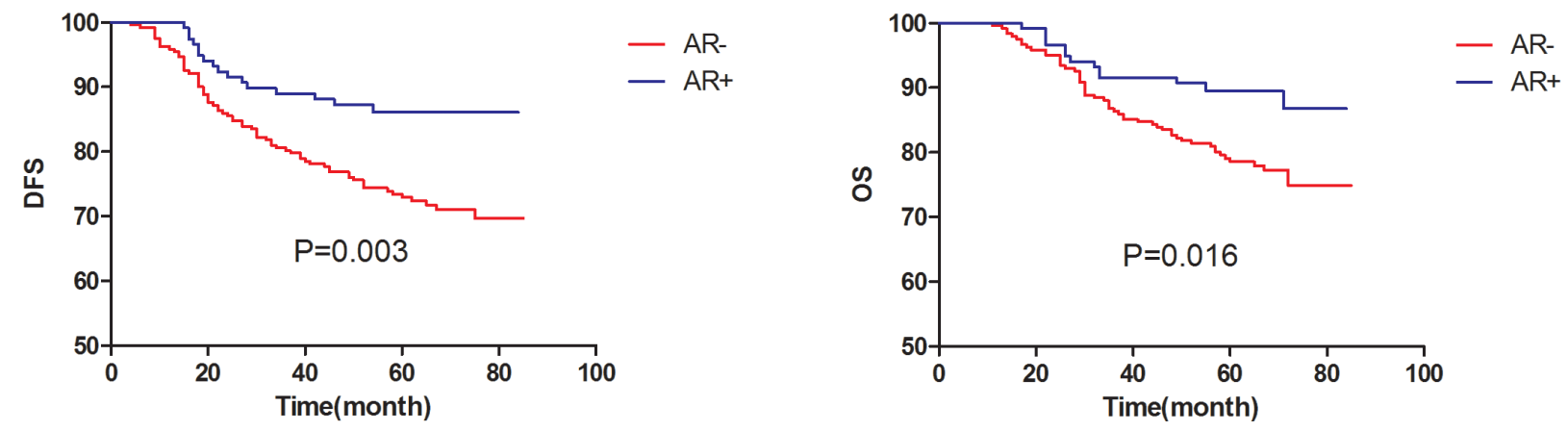

C
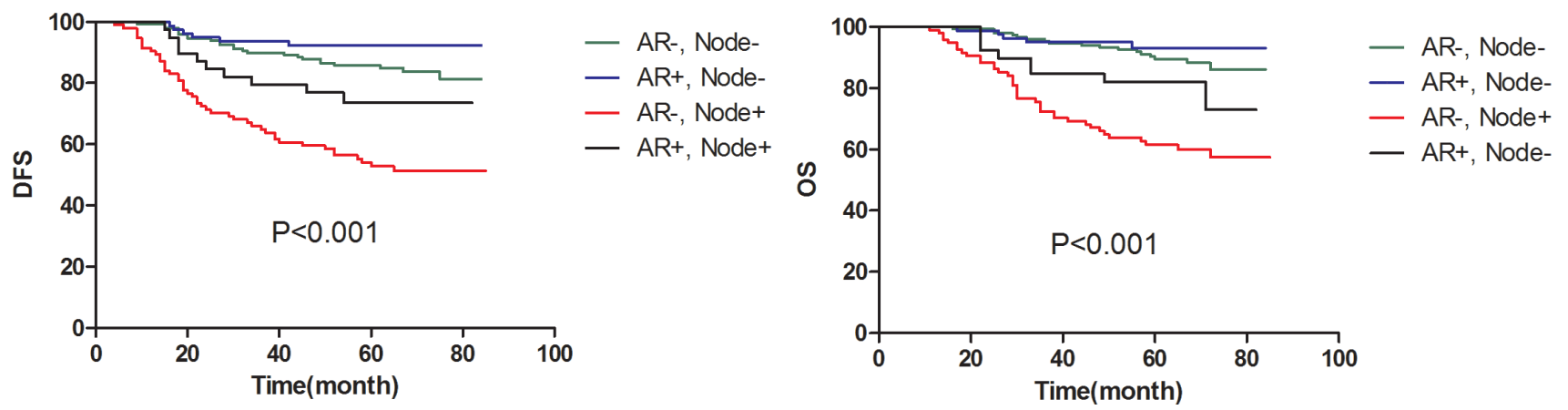

Figure 1: The distributions of the survival curves by androgen receptor in 360 TNBC patients. (A) DFS according to patient category by AR; (B) OS according to patient category by AR; (C) DFS according to patient category by AR and node status; (D) OS according to patient category by AR and node status. 
Table 3A: Hazard ratio of relapse-free survival according to AR status in patient subgroups

\begin{tabular}{|c|c|c|c|c|c|c|}
\hline \multirow{3}{*}{$\begin{array}{l}\text { Subgroup } \\
\text { Overall }\end{array}$} & \multicolumn{2}{|c|}{ No.of patients } & \multirow{2}{*}{\multicolumn{3}{|c|}{ Harzard Ratio(95\% CI) }} & \multirow{3}{*}{$\frac{\text { P value }}{0.005}$} \\
\hline & \multirow{2}{*}{$\frac{\text { AR- }}{242}$} & \multirow{2}{*}{$\frac{\mathbf{A R +}}{118}$} & & & & \\
\hline & & & $0.455(0.264-0.788)$ & $\mapsto$ & 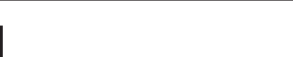 & \\
\hline \multicolumn{7}{|l|}{ Age } \\
\hline$<40$ & 30 & 11 & $0.645(0.137-3.044)$ & $\longmapsto$ & & 0.580 \\
\hline $40-60$ & 154 & 74 & $0.344(0.162-0.729)$ & $\mapsto$ & & 0.005 \\
\hline$>60$ & 58 & 33 & $0.669(0.262-1.711)$ & 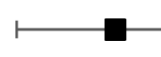 & -1 & 0.402 \\
\hline \multicolumn{7}{|c|}{ Menopausal status } \\
\hline Pre & 110 & 40 & $0.230(0.070-0.751)$ & $\mapsto$ & & 0.015 \\
\hline Post & 132 & 78 & $0.599(0.319-1.128)$ & $\longmapsto$ & H & 0.113 \\
\hline \multicolumn{7}{|l|}{ Tumor size } \\
\hline$<2 \mathrm{~cm}$ & 117 & 67 & $0.550(0.235-1.287)$ & $\longmapsto$ & $\longrightarrow$ & 0.168 \\
\hline $2-5 \mathrm{~cm}$ & 125 & 51 & $0.440(0.216-0.899)$ & $\longmapsto$ & & 0.024 \\
\hline \multicolumn{7}{|l|}{ Node status } \\
\hline 0 & 148 & 79 & $0.473(0.193-1.158)$ & $\vdash$ & $\longrightarrow$ & 0.101 \\
\hline $1-3$ & 52 & 22 & $0.463(0.133-1.610)$ & 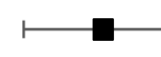 & -1 & 0.226 \\
\hline $4+$ & 42 & 17 & $0.427(0.188-0.971)$ & $\longmapsto$ & & 0.042 \\
\hline \multicolumn{7}{|l|}{ Stage } \\
\hline I & 76 & 49 & $0.632(0.198-2.016)$ & $\vdash$ & $\hookrightarrow$ & 0.438 \\
\hline II & 124 & 52 & $0.413(0.159-1.071)$ & $\longmapsto$ & H & 0.069 \\
\hline III & 42 & 17 & $0.427(0.188-0.971)$ & $\longmapsto$ & & 0.042 \\
\hline \multicolumn{7}{|l|}{ Grade } \\
\hline I-II & 137 & 49 & $0.717(0.369-1.393)$ & & $\longrightarrow$ & 0.327 \\
\hline III & 105 & 69 & $0.268(0.103-0.696)$ & $\mapsto$ & & 0.007 \\
\hline \multicolumn{7}{|c|}{ Vascular invasion } \\
\hline- & 185 & 92 & $0.557(0.286-1.085)$ & $r$ & - & 0.085 \\
\hline+ & 57 & 26 & $0.301(0.116-0.788)$ & $\mapsto$ & & 0.013 \\
\hline \multicolumn{7}{|l|}{ P53 } \\
\hline- & 107 & 36 & $0.777(0.357-1.692)$ & $\longmapsto$ & $\longrightarrow$ & 0.525 \\
\hline+ & 135 & 82 & $0.322(0.150-0.690)$ & $\mapsto$ & & 0.004 \\
\hline \multicolumn{7}{|l|}{ CK5/6 } \\
\hline- & 133 & 81 & $0.404(0.202-0.809)$ & $\mapsto$ & & 0.011 \\
\hline+ & 109 & 37 & $0.576(0.239-1.389)$ & $\longmapsto$ & & 0.220 \\
\hline \multicolumn{7}{|l|}{ Ki-67 } \\
\hline$<15 \%$ & 57 & 26 & $1.096(0.411-2.920)$ & & - & 0.855 \\
\hline $15 \%-50 \%$ & 74 & 55 & $0.441(0.188-1.033)$ & $\longmapsto$ & -1 & 0.059 \\
\hline $50 \%-100 \%$ & 111 & 37 & $0.230(0.071-0.747)$ & $\begin{array}{l}\text { Favors AR } \\
\text { Fan }\end{array}$ & $\mathrm{IR}=1.0$ Favors AR- & 0.015 \\
\hline
\end{tabular}

$\mathrm{AR}$, androgen receptor; $\mathrm{CI}$, confidence interval; HR, hazard ratio. 
Table 3B: Hazard ratio of overall survival according to AR status in patient subgroups

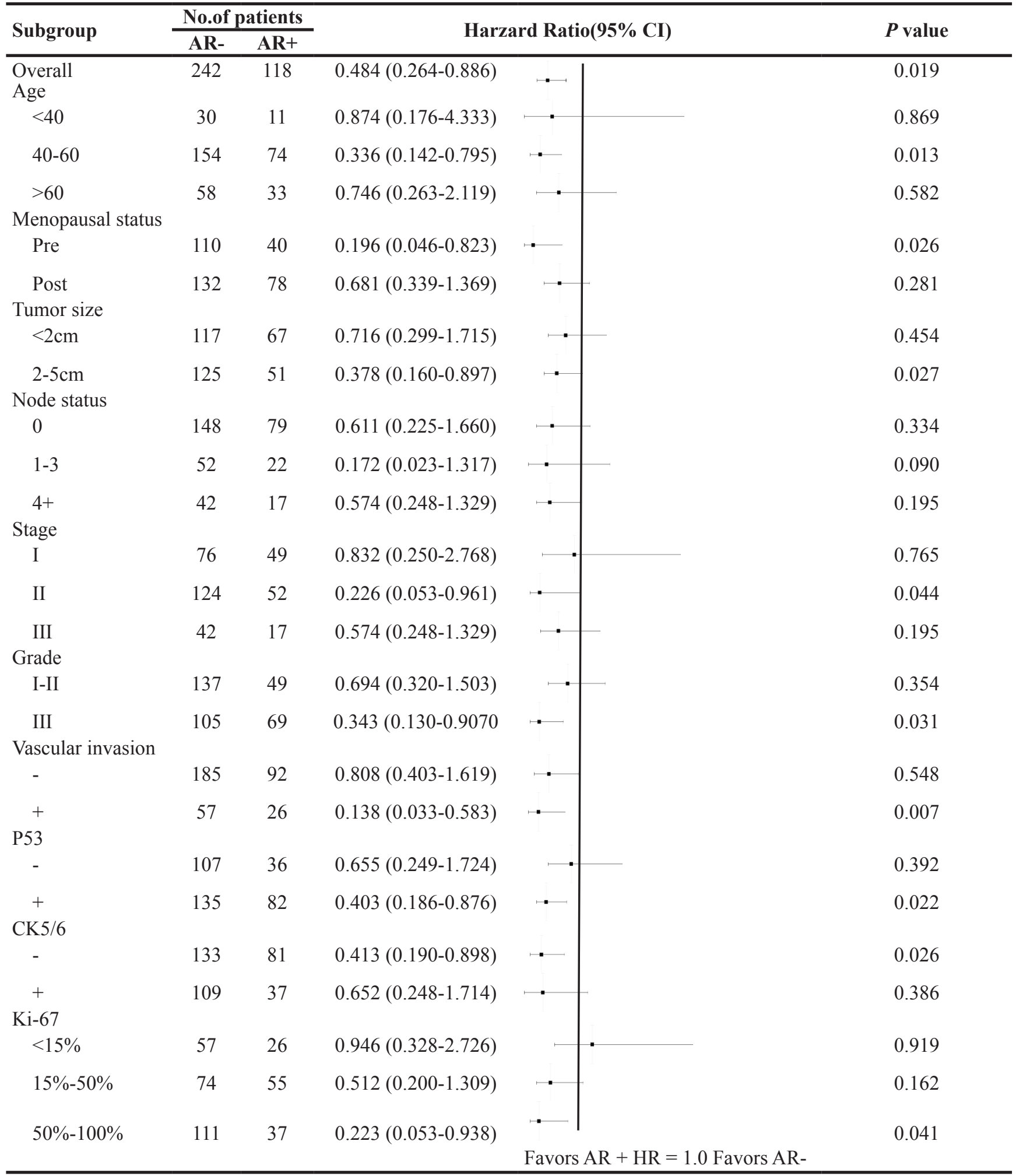

$\mathrm{AR}$, androgen receptor; $\mathrm{CI}$, confidence interval; HR, hazard ratio.

showed that TNBC could be classified into 7 subtypes by gene expression microarray including two basal-like (BL1 and BL2), an immunomodulatory (IM), a mesenchymal (M), a mesenchymal stem-like (MSL), a luminal androgen receptor (LAR) and an unstable (UNS) subtype [4]. One of a well-known subtype, the LAR is heavily enriched in hormonally regulated pathways showed less response to chemotherapy and delayed recurrences compared with the other groups [5], suggesting that it has a clearly different clinical process. 
One of the main characteristics of LAR is the expression of AR, a hormonal receptor that can be evaluated through IHC. AR is a commonly expressed biomarker in both normal breast and breast cancer tissues. In $\mathrm{TNBC}$, the prevalence of AR positivity varies among literatures, depending on different thresholds of positivity. While some studies use a cut-off value of $1 \%$ staining $[10$, 13], many studies use a cut-off value of 5\% [14] or $10 \%$ [15-17]. In this study, we found AR positivity in $31.4 \%$ of patients with a cut-off value of $10 \%$. Remarkably, higher proportion of positive AR were most likely observed in patients with CK5/6-. Since CK5/6 is a well-known biomarker of basal-like subtype (BLBC), our study is consistent with previous studies that basal-like TNBCs have the least expression of AR [8]. Furthermore, we also found that AR positivity is associated with a lower Ki-67 index. It might be an indication of why non-basallike TNBC responds less well than basal-like TNBC to chemotherapy, as discussed previously $[16,18]$. Taken together, the expression of AR might identify certain TNBC molecular subtypes.

The prognostic value of $\mathrm{AR}$ still remains controversial. Some studies showed that TNBC patients with positive AR expression having poor overall survival $[10,14,19]$, however, some other study drawn opposite conclusion [14]. A recent meta-analysis included 2826 TNBC patients showed an association of improved survival outcomes and AR expression in patients with TNBC [9]. In agreement with this study, we have demonstrated that AR showed an independent prognostic value for both DFS $(\mathrm{HR}=0.467)$ and $\mathrm{OS}(\mathrm{HR}=0.488)$. Patients with AR+ and node- has favorable outcome with an observed 5-year DFS of $92 \%$ and an observed 5-year OS of $93 \%$, which is almost 1.5-2 times higher than patients with AR- and node+. Furthermore, in subgroup analyses, AR positivity was significantly correlated to a better survival in patients with young, pre-menopausal, large tumor size, more node involvement (4+), high stage, high grade, vascular invasion+, P53+, CK5/6-, and higher Ki-67. Our findings have indicated that expression of AR reveals tumor of better biological behavior in high-risk TNBC. The contradictory result of prognostic value of AR might correlate to the potential antagonizing effect of AR against ER signaling. It is believed that without functional ER, AR may be the primary driver that facilitate cancer progression [20]. It is reported that with ER expression less than $10 \%$, AR expression incurred better prognosis irrespective of ER co-expression [21]. Since cut-off point of this study is only $1 \%$, the mutual influence of ER versus AR could be negligible which makes our study reliable. Furthermore, one other possible explanation is the different cutoff value of AR. In Wang's meta-analysis, the cutoff value for AR positivity was reported in $10(76.9 \%)$ of 12 studies: one study $(7.7 \%)$ used $0 \%$, three studies $(23.1 \%)$ used $1 \%$, one study $(7.7 \%)$ used $5 \%$, and four studies $(30.8 \%)$ used $10 \%$. Remarkably, the low cut-offs $(1 \%$ or $5 \%)$ or high cut-offs used in different studies did not affected the prognostic value of AR. In our study, we tried $1 \%, 5 \%$ and $10 \%$ as cutoff values. However, only about $10 \%$ of patients were consider as $1 \%-5 \%$ positivity of AR, and the different cut-offs did not affect the main conclusion of this study. In consistent with most studies, we choose $10 \%$ as the cutoff of AR in this manuscript. Another interference factor is the regimens of adjuvant chemotherapy for TNBCs. CEF and CEF-T were used in this study according to guideline at the treating time; however, the dose-dense AC followed by paclitaxel chemotherapy might be more suitable for TNBC according to present version of NCCN guideline. Since there were not survival difference in patients treated with CEF or CEF-T, we believed that the treatment regimen will not influence the prognostic value of AR.

The expression of AR is associated with a luminal subtype as determined by gene microarray, while the majority of AR negative TNBC exhibit a basal-like molecular subtype. In fact, gene-expression profiling has not fully replaced classical IHC yet, since it is not a routine practice. Thus, surrogate IHC markers have served as a more practical means of a preclinical and clinical predictive effect on patient outcome and differential response to specific agents. AR- TNBC, also known as quadruple negative breast cancer (QNBC), has revealed a different gene expression compared with $\mathrm{AR}+\mathrm{TNBC}$ $[8,22]$. Our study has also provided clinical evidence highlighting the necessity of redefining TNBC as AR+ or QNBC. More importantly, AR has recently been developed as a potential therapeutic target. Recently, a phase II trial of bicalutamide, an androgen antagonist, has shown a clinical benefit rate of $19 \%$ in a select group of patients with ER/PgR-negative, AR-positive breast cancer [23]. Other studies and new agents of androgen blockade might also play important roles in developing new therapeutic strategy for TNBC (such as NCT00468715, NCT00516542, NCT01597193).

In conclusion, we have provided another evidence of the relationship between AR and patient survival in TNBC. The redefinition of QNBC that distinguished from TNBC by the absence of AR might help to identify patients with relatively higher risk of disease relapse and death. For AR+ TNBC, the developing of anti-androgen treatment might help to enrich therapeutic strategy for TNBC in clinical practice, however, it is still far from mature. Future studies refer to gene expression, signal pathways and biomarkers in different subtypes of TNBC are required for developing new therapeutic targets.

\section{PATIENTS AND METHODS}

\section{Study population}

From January 2009 to December 2011, 2143 patients with operable invasive breast cancer received curative surgery at Wenzhou Central Hospital and Yue Yang Hospital of Traditional Chinese\&Western Medicine. We 
retrospectively collected data of clinical and pathological characteristics from 360 consecutive cases diagnosed with TNBC confirmed by immunohistochemistry (IHC) test. Since most of the patients with T3-T4 primary tumor underwent neoadjuvant chemotherapy in our centers, only T1-T2 disease were included in this study. Other exclusion criteria included bilateral breast cancer and male breast cancer.

\section{Treatment and follow up}

Mastectomy or BCS was performed to all patients in this study. Axillary node involvement was evaluated by sentinel node biopsy or axillary lymph node dissection at the discretion of treating surgeon according to NCCN guideline. For most of the patients, adjuvant chemotherapy were administered within one month after operation with a total of 6-8 cycles. The adjuvant chemotherapy regimens include CEF (cyclophosphamide+epirubicin+5-fluorouracil), and CEF-T, (cyclophosphamide+epirubicin+5-fluorouracil followed by taxol) with standard dosage according to NCCN guideline. Radiation therapy was offered according to the treating radiation oncologist. All patients were followed-up every 3 months for the first year and then every 6 months until death.

\section{Immunohistochemistry}

Immunohistochemistry (IHC) was performed on formalin-fixed, paraffin-embedded tissue sections from tumor specimens using standard procedures to evaluate biomarkers, including ER, PR, HER-2, Ki-67, P53, CK5/6 and AR. The cut-off value for ER positivity and PR positivity was $1 \%$ of tumor cells with positive nuclear staining. HER-2 was evaluated as $0,1+, 2+$ or $3+$ using circumferential membrane-bound staining [HercepTest (Dako Cytomation, Carpinteria, CA, US)]. Positivity for HER-2 (HER-2+) was considered as $3+$ using IHC or as positive on fluorescence in situ hybridization (FISH), whereas cases with 0 to $1+$ or $2+$ using IHC but without FISH detection were regarded as negative for HER-2 (HER-2-). Only tumors that were ER-, PR- and HER2 - were considered as TNBC and were included in this study. The Ki-67 value was expressed as the percentage of positive cells (at least 1000) with nuclear staining in each case. CK5/6 was considered positive if $10 \%$ or more of the tumor cells showed positive membrane expression. The examination of P53 and AR expression was assessed on the basis of nuclear staining intensity, and more than $10 \%$ of tumor cell nuclei stained were considered positive.

\section{Statistics}

The Chi-squared test was used to evaluate the relationship between the patient characteristics and AR status. Disease-free survival (DFS) was defined as the length of time from the date of operation to events (local relapse or distant metastasis disease, occurrence of a new primary tumor or death without evidence of cancer). OS was defined as the length of time from the date of operation to death. Patients without any event or death were censored at the time of last follow-up. Univariate and multivariate survival analyses were performed by using the Cox regression model. Hazard ratio (HR) and 95\% confidence interval (CI) were presented. Survival curves were estimated using the Kaplan-Meier method, and the log-rank test was used to test for differences between groups. All P-values reported were two sided and were calculated at a significance level of 0.05. All statistical procedures were carried out using SPSS (version 13.0; SPSS Company, Chicago, IL).

\section{Abbreviations}

AR, androgen receptor

TNBC, triple-negative breast cancer

HER-2, epidermal growth factor receptor-2

$\mathrm{ER}$, expression of estrogen receptor

$\mathrm{PR}$, progesterone receptor

IHC, immunohistochemistry

LAR, luminal androgen receptor

$\mathrm{CEF}$, Cyclophosphamide+epirubicin +5 -fluorouracil

CEF-T, Cyclophosphamide+epirubicin+5-

fluorouracil followed by taxol

DFS, Disease-free survival

OS, overall survival

HR, Hazard ratio

CI, confidence interval

BL, basal-like

IM, immunomodulatory

M, mesenchymal

MSL, mesenchymal stem-like

UNS, unstable

QNBC, quadruple negative breast cancer

\section{Author contributions}

Xiao-Qing Hu \& Ke Jiang, design this study and write this manuscript.

\section{ACKNOWLEDGMENTS}

This research was supported by a grant from the Shanghai Municipal Commission of Health and Family Planning (201540234). The funders had no role in the study design, data collection and analysis, decision to publish, or preparation of the manuscript.

\section{CONFLICTS OF INTEREST}

The authors declare no potential conflicts of interest, and there are no financial disclosures. 
Wei-Li Chen, collected and analyzed the data

Hai-Guang Ma, statistics and edited table and figure

\section{REFERENCES}

1. Coates AS, Winer EP, Goldhirsch A, Gelber RD, Gnant M, Piccart-Gebhart M, Thurlimann B, Senn HJ. Tailoring therapies--improving the management of early breast cancer: St Gallen International Expert Consensus on the Primary Therapy of Early Breast Cancer 2015. Ann Oncol. 2015; 26:1533-1546.

2. Bauer KR, Brown M, Cress RD, Parise CA, Caggiano V. Descriptive analysis of estrogen receptor (ER)-negative, progesterone receptor (PR)-negative, and HER2-negative invasive breast cancer, the so-called triple-negative phenotype: a population-based study from the California cancer Registry. Cancer. 2007; 109:1721-1728.

3. Murria R, Palanca S, de Juan I, Alenda C, Egoavil C, Segui FJ, Garcia-Casado Z, Juan MJ, Sanchez AB, Segura A, Santaballa A, Chirivella I, Llop M, et al. Immunohistochemical, genetic and epigenetic profiles of hereditary and triple negative breast cancers. Relevance in personalized medicine. Am J Cancer Res. 2015; 5:2330-2343.

4. Lehmann BD, Bauer JA, Chen X, Sanders ME, Chakravarthy AB, Shyr Y, Pietenpol JA. Identification of human triple-negative breast cancer subtypes and preclinical models for selection of targeted therapies. J Clin Invest. 2011; 121:2750-2767.

5. Masuda H, Baggerly KA, Wang Y, Zhang Y, GonzalezAngulo AM, Meric-Bernstam F, Valero V, Lehmann BD, Pietenpol JA, Hortobagyi GN, Symmans WF, Ueno NT. Differential response to neoadjuvant chemotherapy among 7 triple-negative breast cancer molecular subtypes. Clin Cancer Res. 2013; 19:5533-5540.

6. Lehmann BD, Jovanovic B, Chen X, Estrada MV, Johnson KN, Shyr Y, Moses HL, Sanders ME, Pietenpol JA. Refinement of triple-negative breast cancer molecular subtypes: implications for neoadjuvant chemotherapy selection. PLoS One. 2016; 11:e0157368.

7. McNamara KM, Yoda T, Takagi K, Miki Y, Suzuki T, Sasano H. Androgen receptor in triple negative breast cancer. J Steroid Biochem Mol Biol. 2013; 133:66-76.

8. Hon JD, Singh B, Sahin A, Du G, Wang J, Wang VY, Deng FM, Zhang DY, Monaco ME, Lee P. Breast cancer molecular subtypes: from TNBC to QNBC. Am J Cancer Res. 2016; 6:1864-1872.

9. Wang C, Pan B, Zhu H, Zhou Y, Mao F, Lin Y, Xu Q, Sun Q. Prognostic value of androgen receptor in triple negative breast cancer: a meta-analysis. Oncotarget. 2016; 7:4648246491. doi: 10.18632/oncotarget.10208.

10. Choi JE, Kang SH, Lee SJ, Bae YK. Androgen receptor expression predicts decreased survival in early stage triple-negative breast cancer. Ann Surg Oncol. 2015; 22:82-89.
11. Jiang HS, Kuang XY, Sun WL, Xu Y, Zheng YZ, Liu YR, Lang GT, Qiao F, Hu X, Shao ZM. Androgen receptor expression predicts different clinical outcomes for breast cancer patients stratified by hormone receptor status. Oncotarget. 2016; 7:41285-41293. doi: 10.18632/ oncotarget.9778.

12. Carey LA, Dees EC, Sawyer L, Gatti L, Moore DT, Collichio F, Ollila DW, Sartor CI, Graham ML, Perou CM. The triple negative paradox: primary tumor chemosensitivity of breast cancer subtypes. Clin Cancer Res. 2007; 13:2329-2334.

13. Hu R, Dawood S, Holmes MD, Collins LC, Schnitt SJ, Cole K, Marotti JD, Hankinson SE, Colditz GA, Tamimi RM. Androgen receptor expression and breast cancer survival in postmenopausal women. Clin Cancer Res. 2011; 17:1867-1874.

14. He J, Peng R, Yuan Z, Wang S, Peng J, Lin G, Jiang X, Qin T. Prognostic value of androgen receptor expression in operable triple-negative breast cancer: a retrospective analysis based on a tissue microarray. Med Oncol. 2012; 29:406-410.

15. McGhan LJ, McCullough AE, Protheroe CA, Dueck AC, Lee JJ, Nunez-Nateras R, Castle EP, Gray RJ, Wasif N, Goetz MP, Hawse JR, Henry TJ, Barrett MT, et al. Androgen receptor-positive triple negative breast cancer: a unique breast cancer subtype. Annals of surgical oncology. 2014; 21:361-367.

16. Pistelli M, Caramanti M, Biscotti T, Santinelli A, Pagliacci A, De Lisa M, Ballatore Z, Ridolfi F, Maccaroni E, Bracci R, Berardi R, Battelli N, Cascinu S. Androgen receptor expression in early triple-negative breast cancer: clinical significance and prognostic associations. Cancers (Basel). 2014; 6:1351-1362.

17. Park S, Koo JS, Kim MS, Park HS, Lee JS, Lee JS, Kim SI, Park BW, Lee KS. Androgen receptor expression is significantly associated with better outcomes in estrogen receptor-positive breast cancers. Ann Oncol. 2011; 22:1755-1762.

18. Barton VN, D'Amato NC, Gordon MA, Christenson JL, Elias A, Richer JK. Androgen receptor biology in triple negative breast cancer: a case for classification as AR+ or quadruple negative disease. Horm Cancer. 2015; 6:206-213.

19. Qu Q, Mao Y, Fei XC, Shen KW. The impact of androgen receptor expression on breast cancer survival: a retrospective study and meta-analysis. PLoS One. 2013; 8:e82650.

20. De Amicis F, Thirugnansampanthan J, Cui Y, Selever J, Beyer A, Parra I, Weigel NL, Herynk MH, Tsimelzon A, Lewis MT, Chamness GC, Hilsenbeck SG, Ando S, Fuqua SA. Androgen receptor overexpression induces tamoxifen resistance in human breast cancer cells. Breast Cancer Res Treat. 2010; 121:1-11.

21. Vera-Badillo FE, Templeton AJ, de Gouveia P, Diaz-Padilla I, Bedard PL, Al-Mubarak M, Seruga B, Tannock IF, Ocana A, Amir E. Androgen receptor expression and outcomes in 
early breast cancer: a systematic review and meta-analysis. J Natl Cancer Inst. 2014; 106:djt319.

22. Doane AS, Danso M, Lal P, Donaton M, Zhang L, Hudis C, Gerald WL. An estrogen receptor-negative breast cancer subset characterized by a hormonally regulated transcriptional program and response to androgen. Oncogene. 2006; 25:3994-4008.
23. Gucalp A, Tolaney S, Isakoff SJ, Ingle JN, Liu MC, Carey LA, Blackwell K, Rugo H, Nabell L, Forero A, Stearns V, Doane AS, Danso M, et al. Phase II trial of bicalutamide in patients with androgen receptor-positive, estrogen receptornegative metastatic Breast Cancer. Clin Cancer Res. 2013; 19:5505-5512. 